\title{
Hypertension in Saudi Adults with Type 2 Diabetes
}

\author{
Khalid S Aljabri' ${ }^{1 *}$, Samia A Bokhari ${ }^{1}$ and Bandari K Aljabri² \\ 1Department of Endocrinology, King Fahad Armed Forces Hospital, Saudi Arabia \\ 2College of medicine, Um Al Qura University, King Fahad Armed Forces Hospital, Saudi Arabia \\ *Corresponding author: Eduardo Guimarães Hourneaux de Moura, Endoscopy Unit, Hospital das Clínicas, University of São Paulo School of Medicine, \\ USA
}

Submission: 海 April 03, 2018; Published: 酱 May 10, 2018

Keywords: Diabetes; Hypertension

\section{Introduction}

Type 2 diabetes mellitus (T2DM) and Hypertension (HTN) are among the most common chronic non-communicable diseases and multi factorial disorders affecting both developed and developing countries and occur at a higher prevalence in the older age group and result from both genetic and environmental etiological factors [1-3]. HTN is considered as one of the most common diseases with high value of mortality and morbidity and is considered the leading risk factor for morbidity and mortality in Saudi Arabia [4]. The prevalence of HTN is rapidly increasing in developing countries and is said to be one of the leading causes of death and disability among the elderly [5-11]. The World Health Organization reported that 1 out of 10 adults have diabetes; however, in Saudi Arabia, the ratio is one out of four adults [12]. Previous studies in 2011 in Saudi Arabia showed that $23.1-30 \%$ of the adults have diabetes [13-14]. Although T2DM and HTN are not among the top leading causes of death, such as cancer and stroke, these two diseases draw attention from the public due to their increasing trends, while cancer and stroke are declining [15]. Several studies conducted in different ethnic groups show a close association between HTN and T2DM, where the prevalence of HTN is significantly higher in the patients with T2DM. Both systolic and diastolic HTN has been reported, and conclusive evidence indicates that the link between T2DM and essential HTN is hyperinsulinemia [16]. The prevalence of HTN is 1.5-2.0 times more in those with T2DM than in those without T2DM, whereas almost one-third of the patients with HTN develop T2DM later [17]. Therefore, the aim of the present study is to determine the frequency of T2DM and HTN among the patients who have attended the primary health care centre in a Saudi community.

\section{Methods}

A cross sectional study was conducted at Primary health care clinics at king fahad armed forces hospital. A total of 2519 Saudi diabetic and non diabetic patients were randomly selected. The 
demographic data and medical history were documented. Blood Pressure readings were within a gap of 15 minutes using a mercury sphygmomanometer by palpation and auscultation method in right arm in sitting position. Two readings were taken 15 min apart and the average of both the readings was taken for analysis. HTN was also diagnosed based on anti HTN medications or having a prescription of antihypertensive drugs and were classified as Hypertensive irrespective of their current blood pressure reading or if the blood pressure was greater than $140 / 90 \mathrm{mmHg}$ i.e. systolic BP more than 140 and diastolic BP more than 90 mm of Hg - Report of the American College of Cardiology/American Heart Association Task Force on Clinical Practice Guidelines [18]. The Body mass index (BMI) was considered normal if it was below $25 \mathrm{~kg} / \mathrm{m}^{2}, 25-29.9 \mathrm{~kg} /$ $\mathrm{m}^{2}$ overweight and $30 \mathrm{~kg} / \mathrm{m}^{2}$ or greater was obese. The study was approved by the ethical board of King Fahad armed forces hospital.

\section{Statistical Analysis}

Univariate analysis of baseline and follow up demography and clinical laboratory endpoints were accomplished using unpaired t-test. Chi square(X2) test were used for categorical data comparison. All statistical analyses were performed using SPSS
Version 22.0. All $\mathrm{P}$ values were based on two-sided tests. $\mathrm{P}<0.05$ was considered significant.

\section{Results}

A total of 3108 patients attending the Primary Health Care Clinics were included in this study, 1148 (36.9\%) male and 1960 (63.1\%) female. The diabetic group comprised of 1740 (56.0\%) and non-diabetic group comprised of 1368 (44.0\%) of the sample. T2DM and HTN was present in 981 (56.4\%) of cases, (Table 1). The T2DM and HTN cases showed a female predominance (sex ratio female: male=1.5:1). The mean age of the participants was 42.2 \pm 17.9 years. Cases with T2DM and HTN were significantly older. HbA1c was not significantly different between cases with T2DM and HTN compared to cases with T2DM with no HTN. Figure 1 shows that around one third of the T2DM and HTN cases were in the age group of 50-59 years while about $38.4 \%$ were older than 60 years with both male and female predominance. Figure 2 shows that $55.6 \%$ of the T2DM and HTN cases were obese BMI $\geq 30$ with male predominance, Furthermore, $99.6 \%$ of cases with female predominance with BMI starting 18.5-24.9.

Table 1: Demographic patient's parameters and Comparison of features between diabetics and hypertension

\begin{tabular}{|c|c|c|c|c|}
\hline \multirow{2}{*}{\multicolumn{2}{|c|}{ Parameters }} & \multicolumn{2}{|c|}{ Diabetes Associated Hypertension } & \multirow{2}{*}{ P Value } \\
\hline & & Yes & No & \\
\hline \multirow{2}{*}{ Gender } & Male & $397(53.1)$ & $351(46.9)$ & \multirow{2}{*}{0.02} \\
\hline & Female & $584(58.9)$ & $408(41.1)$ & \\
\hline \multicolumn{2}{|c|}{ Age(years) } & $59.3 \pm 11.4$ & $50.4 \pm 13.2$ & $<0.0001$ \\
\hline \multicolumn{2}{|c|}{$\mathrm{HbA1c}$} & $8.6 \pm 1.8$ & $8.5 \pm 1.9$ & 0.8 \\
\hline
\end{tabular}

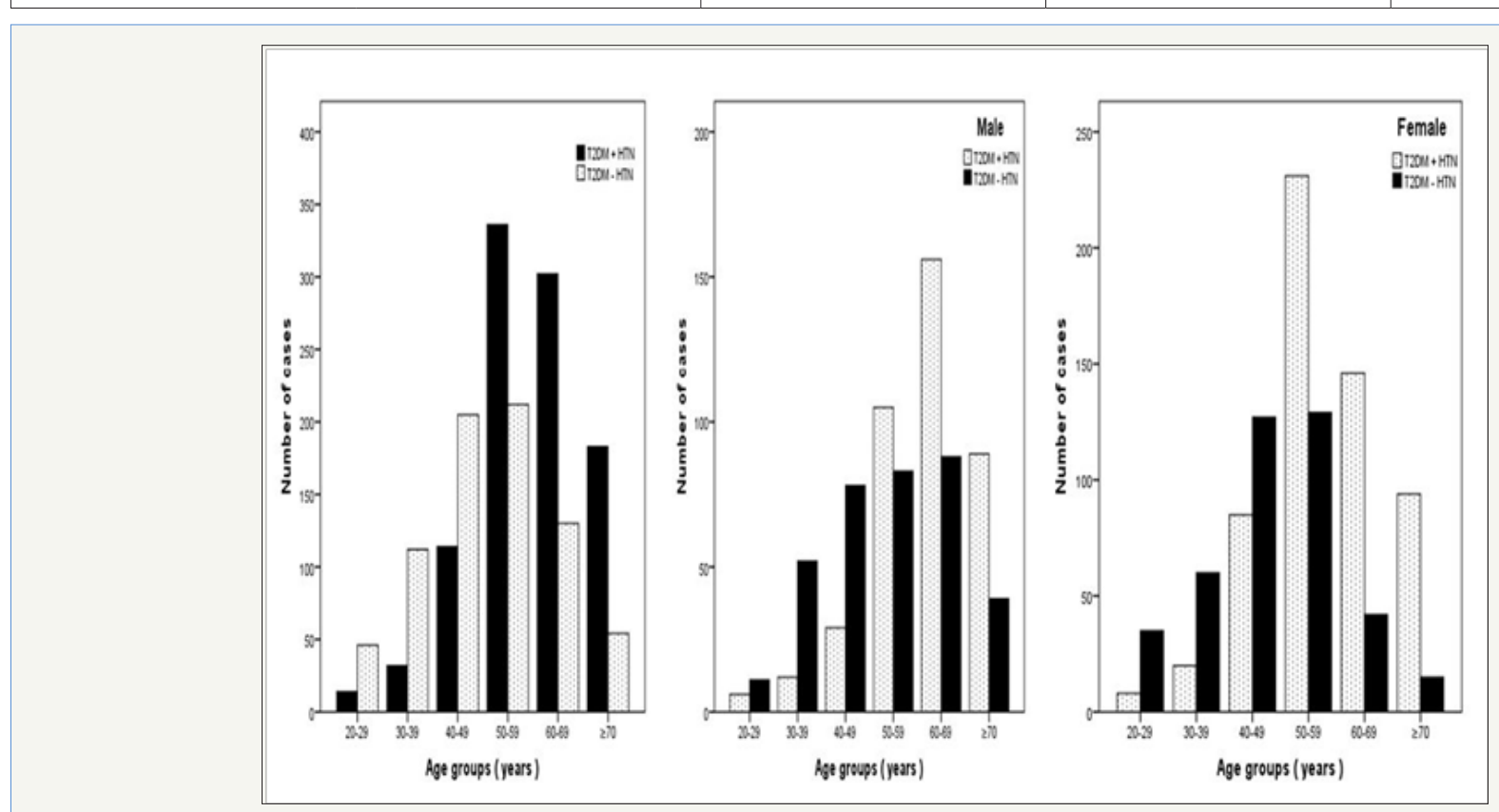

Figure 1: Frequency of T2DM and HTN according to age groups 


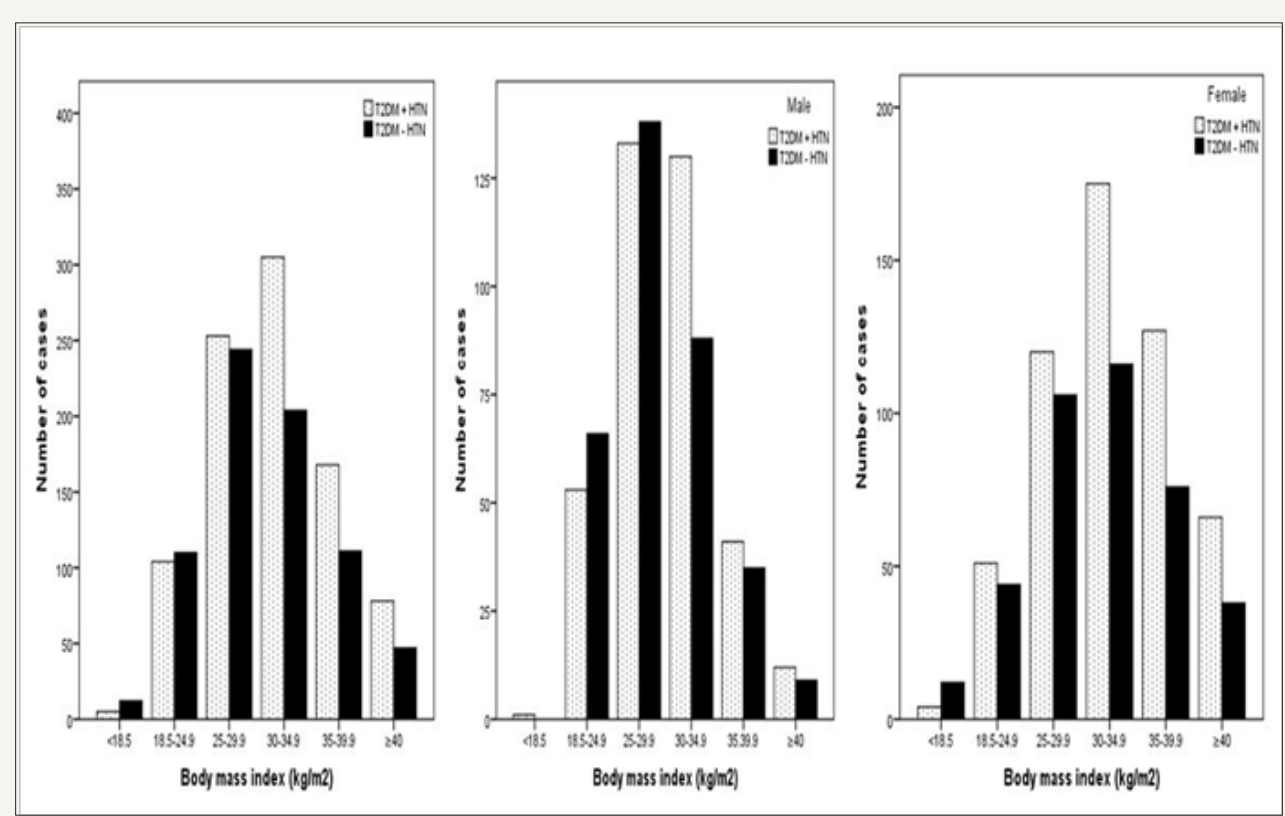

Figure 2: Frequency of T2DM and HTN according to body mass index groups.

\section{Discussion}

Hypertension is a common problem for people with diabetes. There is much evidence for an increased prevalence of hypertension in diabetic persons [19]. The prevalence rate of hypertension among type 2 diabetics is higher than that of age and sex-matched patients without diabetes, ranging between $32 \%$ and $82 \%$. Compared to Arab population, the prevalence rate of hypertension reported in this study (56.4\%) among patients with type 2 diabetes is lower to the $64.5 \%$ rate reported in Qatari diabetics and $72.4 \%$ rate reported in Jordanian diabetics. In other Arab populations, the prevalence rate of hypertension is moderate: $53 \%$ in Saudi diabetics, $44 \%$ in Omani diabetics and 38\% in Bahraini diabetics. Compared to other populations, the rate of hypertension among diabetics in our study is lower to the $74 \%, 74.4 \%$ and $73 \%$ rates of hypertension reported in UK Caucasians, Italian and Spanish populations, respectively. This prevalence is lower than the $82 \%$ prevalence rate reported about Afro-Caribbean individuals living in UK and much higher than the $32 \%$ and $39 \%$ rates reported among diabetics in the Turkish and Taiwanese populations, respectively. The explanation for differences in frequency by each country could be due to different methods of surveillance, differences in definitions of hypertension, population characteristics and ethnic variations. Hyperglycemia and increase in total body exchangeable sodium leading to extracellular fluid accumulation and expansion of the plasma volume contributes to the pathogenesis of hypertension in DM [20-30].

The coexistence of HTN and T2DM is major risk factors to the development and progression of macro vascular and micro vascular complications in people with diabetes compared to the general population [31-34]. Both HTN and T2DM increase the risks of cardiovascular disease, stroke, nephropathy and retinopathy [34-39]. Indeed when hypertension coexists with diabetes, the risk of cardiovascular disease is increased by 75\%, which further contributes to the overall morbidity and mortality of an already high risk population. The relatively higher rate of hypertension reported in this study is related to the fact that most diabetic patients were aged 60 years old and over. Hypertension among type 2 diabetics was associated with age; this association agrees with so many studies [40-43].

Our study also showed that obese and overweight patients have a higher risk of hypertension than ones with normal BMI, this association is in agreement with research literatures and with the findings of other studies. 43 In addition, the coexistence of diabetes, hypertension and obesity or overweight increases the risk of cardiovascular complications and other morbidities [44,45].

The objective of HTN and T2DM care is to reduce its mortality and complications and to improve the quality of life for patients suffering from this chronic health problem. To achieve these aims, it is mandatory to have adequate diagnostic, therapeutic and educational resources in addition to competent physicians who can manage HTN and T2DM by using a continuing, comprehensive and coordinated approach [46]. Management of HTN and T2DM in PHC centres is highly affected by lack of resources and facilities. Many essential resources for the care of patients with HTN and T2DM are not available at primary health care settings [47]. Urgent provision of these resources is essential to introduce good health care for hypertensive patients.

To improve the quality of care for HTN and T2DM patients and to ensure better control, we recommend improvements in primary health care physician knowledge about chronic disease management, updating the national guidelines for management of hypertension and keeping them accessible to doctors in primary health care clinics, improving the quality of the filing system, 
improvement of screening programs and the provision of essential resources for HTN and T2DM care.

Due to the cross sectional nature of this study, the observed population reflects a selected yet comprehensive group of patients Our study could be limited by the question of clustering of cases within the study region and the effect that might have on our estimates, in addition, the current study population may appear limited in size and therefore may underestimate the true frequency of T2DM and HTN in the general population. Despite this limitation, our study is one of the Saudi studies done on a large sample, which was specifically interested in the problem of hypertension in diabetic patients and reported very important information on the epidemiology of hypertension in Saudi diabetics.

In conclusion, the frequency of HTN in patients with T2DM in this study is high. It is mandatory to have adequate diagnostic, therapeutic and educational resources in addition to competent physicians who can manage HTN in T2DM patients by using a continuing, comprehensive and coordinated approach.

\section{References}

1. King RA, Rotter JI, Motulsky AG (1992) The genetic basis of common diseases. Oxford Universtity Press, Oxford, UK.

2. Fraser FC (1980) Evolution of a palatable multifactorial threshold model. Am J Hum Genet 32(6): 796-813.

3. Mueller RF, Young ID (1995) Emery's Elements of Medical Genetics. ( $9^{\text {th }}$ edn), In: Mueller RF, Young ID (Eds.) Emery's Elements of Medical Genetics, Churchill Livingston, London.

4. World Health Organization (2013) A global brief on hypertension. WHO, Geneva, Switzerland.

5. Murray CLJ, Lopez AD (1996) Global health statistics: global burden of diseases and injury series. Harvard school of Public Health Boston 349: 1436-1442.

6. Nakano S, Ito T, Furuya K, Tsuda S, Konishi K, et al. (2004) Ambulatory blood pressure level rather than dipper/nondipper status predicts vascular events in type 2 diabetic subjects. Hypertens Res 27(9): 647656.

7. Salman RA, Al-Rubeaan KA (2009) Incidence and risk factors of hypertension among Saudi type 2 diabetes adult patients: an 11-year prospective randomized study. J Diabetes Complications 23(2): 95-101.

8. Stratton IM, Cull CA, Adler AI, Matthews DR, Neil HA, et al. (2006) Additive effects of glycaemia and blood pressure exposure on risk of complications in type 2 diabetes: a prospective observational study (UKPDS 75). Diabetologia 49(8): 1761-1769.

9. Anderson RJ, Bahn GD, Moritz TE, et al. (2011) VADT Study Group. Blood pressure and cardiovascular disease risk in the Veterans Affairs Diabetes Trial. Diabetes Care 34(1): 34-38.

10. Gaede P, Lund-Andersen H, Parving HH, Pedersen O (2008) Effect of a multifactorial intervention on mortality in type 2 diabetes. N Engl J Med 358(6): 580-591.

11. Bakris GL, Weir MR, Shanifar S, Zhang Z, Douglas J, et al. (2003) Effects of blood pressure level on progression of diabetic nephropathy: results from the RENAAL study. Arch Intern Med 163(13): 1555-1565.

12. Al-Kayyal MA, Halawani SY, Al-Ghalayini RM, Al-Jefri AY, Al-Hazmi N (2013) Dentists may play a pivotal role in the screening of diabetes and hypertension. Forum 1(1): 44-53.

13. Alqurashi KA, Aljabri KS, Bokhari SA (2011) Prevalence of diabetes mellitus in a Saudi community. Ann Saudi Med 31(1): 19-23.
14. Al-Daghri NM, Al-Attas OS, Alokail MS, Alkharfy KM, Yousef M, et al. (2011) Diabetes mellitus Type 2 and other chronic non-communicable diseases in the central region, Saudi Arabia (Riyadh cohort 2): a decade of an epidemic. BMC Med 9: 76.

15. Yoon KH, Lee JH, Kim JW, et al (2006) Epidemic obesity and type 2 diabetes in Asia. Lancet 368(9548): 1681-1688.

16. Sowers JR, Khoury S (1991) Diabetes and hypertension: a review. Prim Care 18(3): 509-524.

17. Sahay BK (2007) API-ICP guidelines on DM. J Assoc Physicians India 55: $1-50$.

18. Whelton PK, Robert MC, Wilbert SA, Donald EC, Karen JC, et al. (2017) ACC/AHA/AAPA/ABC/ACPM/AGS/APhA/ASH/ASPC/NMA/PCNA Guideline for the Prevention, Detection, Evaluation, and Management of High Blood Pressure in Adults: A Report of the American College of Cardiology/American Heart Association Task Force on Clinical Practice Guidelines. Hypertension 71(5).

19. (1994) National High Blood Pressure Education Program Working Group report on hypertension in diabetes. Hypertension 23(2): 145-58.

20. Baskar V, Kamalakannan D, Holland MR, Singh BM (2002) The prevalence of hypertension and utilization of antihypertensive therapy in a district Diabetes Population. Diabetes Care 25(11): 2107-2108.

21. Bener A, Zirie M, Janahi IM, Al-Hamaq AO, Musallam M, et al. (2009) Prevalence of diagnosed and undiagnosed diabetes mellitus and its risk factors in a population-based study of Qatar. Diabetes Res Clin Pract 84(1): 99-106.

22. Mubarak FM, Froelicher ES, Jaddou HY, Ajlouni KM (2008) Hypertension among 1000 patients with type 2 diabetes attending a national diabetes center in Jordan. Ann Saudi Med 28(5): 346-51.

23. Akbar DH, Ahmed MM, Algambi AA (2003) Cardiovascular risk factors in Saudi and non-Saudi diabetics. Saudi Med J 24(6): 686-687.

24. Al-Moosa S, Allin S, Jemiai N, Al-Lawati J, Mossialos E (2006) Diabetes and urbanization in the Omani population: an analysis of national survey data. Popul Health Metr 4: 5.

25. Al-Mahroos F, Al-Roomi K, McKeigue PM (2000) Relation of high blood pressure to glucose intolerance, plasma lipids and educational status in an Arabian Gulf population. Int J Epidemiol 29(1): 71-76.

26. Comaschi M, Coscelli C, Cucinotta D, Malini P, Manzato E, et al. (2005) SFIDA Study Group--Italian Association of Diabetologists (AMD). Cardiovascular risk factors and metabolic control in type 2 diabetic subjects attending outpatient clinics in Italy: the SFIDA (survey of risk factors in Italian diabetic subjects by AMD) study. Nutr Metab Cardiovasc Dis 15(3): 204-211.

27. Del Cañizo-Gómez FJ, Moreira-Andrés MN (2004) Cardiovascular risk factors in patients with type 2 diabetes. Do we follow the guidelines? Diabetes Res Clin Pract 65(2): 125-133.

28. Baskar V, Kamalakannan D, Holland MR, Singh BM (2006) Does ethnic origin have an independent impact on hypertension and diabetic complications? Diabetes Obes Metab 8(2): 214-219.

29. Tseng CH (2006) Higher risk of hypertension in indigenous type 2 diabetic patients in Taiwan. Journal of Hypertension 24(9): 1817-1821.

30. de Châtel R, Weidmann P, Flammer J, Ziegler WH, Beretta-PiccoliC, Vetter W, et al. (1977) sodium, renin, aldosterone, catecholamine's and blood pressure in diabetes mellitus. Kidney Int 12(6): 412-421.

31. Libby P, Nathan DM, Abraham K, Brunzell JD, Fradkin JE, et al. (2005) Report of the National Heart, Lung and Blood Institute: national institute of diabetes and digestive and kidney diseases working group on cardiovascular complications of DM. Circulation 111(25): 3489-3493.

32. Fong DS, Aiello LP, Ferris FL, Klein R (2004) Diabetic retinopathy. Diabetes Care 27(10): 2540-2553. 
33. Tesfaye S, Chaturvedi N, Eaton SE, Ward JD, Manes C, et al. (2005) EURODIAB prospective complicationss tudy group. vascular risk factors and diabetic neuropathy. N Engl J Med 352(4): 341-350.

34. Sowers JR, Williams M, Epstein M, Bakris G (2000) Hypertension in patients with diabetes: strategies for drug therapy to reduce complications. Postgraduate Medicine 107(4):47-60.

35. Sowers JR, Epstein M, Frohlich ED (2001) Diabetes, hypertension, and cardiovascular disease: an update. Hypertension. 37(4): 1053-1059.

36. Sowers JR, Haffner S (2002) Treatment of cardiovascular and renal risk factors in the diabetic hypertensive. Hypertension 40(6): 781-788.

37. Sowers JR (2004) Treatment of hypertension in patients with diabetes. Arch Intern Med chives of Internal Medicine 164(17): 1850-1857.

38. El-Atat F, McFarlane SI, Sowers JR (2004) Diabetes, hypertension, and cardiovascular derangements: pathophysiology and management. Curr Hypertens Rep 6(3): 215-223.

39. Bakris G, Williams M, Dworkin L, Elliott W, Epstein M, et al. (2000) Preserving renal function in adults with hypertension and diabetes: A consensus approach. National Kidney Foundation Hypertension and Diabetes Executive Committees Working Group. Am J kidney Dis 36(3): 646-661.

40. Davis TM, Stratton IM, Fox CJ, Holman RR, Turner RC (1997) U.K. Prospective Diabetes Study 22. Effect of age at diagnosis on diabetic tissue damage during the first 6 years of NIDDM. Diabetes Care 20(9): $1435-1441$.
41. Cowie CC, Harris MI (1995) Physical and metabolic characteristics of persons with diabetes. In: Harris MI (Ed.), Diabetes in America. $\left(2^{\text {nd }}\right.$ edn), Bethesda, Md: National Institutes of Health, National Institutes of Diabetes and Digestive and Kidney Disease, 117-164.

42. Sprafka JM, Bender AP, Jagger HG (1988) Prevalence of hypertension and associated risk factors among diabetic individuals. The Three-City Study. Diabetes Care 11(1): 17-22

43. Hillier TA, Pedula KL (2001) Characteristics of an adult population with newly diagnosed type 2 DM: the relation of obesity and age of onset. Diabetes Care 24(9): 1522-1527.

44. Brown CD, Higgins M, Donato KA, Rohde FC, Garrison R, et al. (2000) Body mass index and the prevalence of hypertension and dyslipidemia. Obes Res 8(9): 605-619.

45. Must A, Spadano J, Coakley EH, Field AE, Colditz G, Dietz WH (1999) The disease burden associated with overweight and obesity. JAMA 282(16): 1523-1529.

46. Sloane PD, Slatt LM, Curtis P (1993) Essentials of Family Medicine (2 $2^{\text {nd }}$ edn), Williams \& Wilkins, Baltimore, Maryland, pp. 245-251.

47. Al-Sharif AI, Al-Khaldi YM (2003) Resource availability for care of hypertensives at primary health settings in Southwestern Saudi Arabia. Saudi Med J 24(5): 466-471.
Creative Commons Attribution 4.0

International License

For possible submissions Click Here
Submit Article

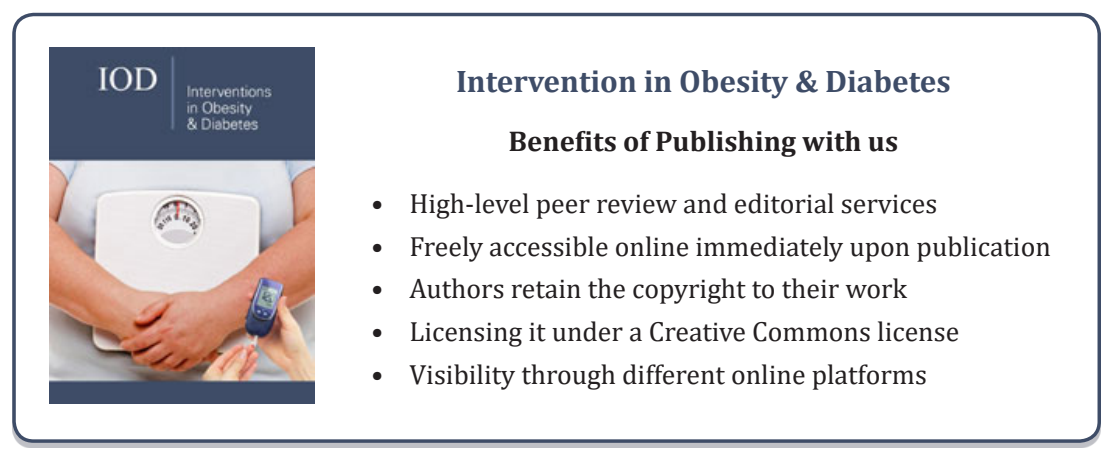

